\title{
Characterisation of local grain size variation of welded structural steel
}

\author{
Pauli Lehto $^{1} \cdot$ Jani Romanoff $^{1} \cdot$ Heikki Remes $^{1} \cdot$ Teemu Sarikka $^{1}$
}

Received: 6 October 2015 / Accepted: 11 February 2016 / Published online: 22 March 2016

(C) The Author(s) 2016. This article is published with open access at Springerlink.com

\begin{abstract}
Previously, it has been shown that the grain size distribution plays an important role in the mechanical properties of welded steel. In the previous investigation, the volume-weighted average grain size has been shown to capture the influence of grain size distribution, resulting in a better fitting Hall-Petch relationship between grain size and hardness. However, the previous studies exclude the effects arising from local variation in grain size. In this paper, the grain size measurement methods are extended for the characterisation of the local grain size variation, which is significant for welded joints and can have an adverse effect on mechanical properties. The local gradient of grain size variation and its dependency on measurement direction are considered. In addition, examples of grain size and hardness variation are shown for S355 base metal and two weld metals, and characteristic differences are highlighted and discussed. The coarse-grained areas of a heterogeneous microstructure are found to have lower hardness than fine-grained areas. However, the surrounding microstructure, i.e. local grain size gradient, has an influence on the measured hardness values.
\end{abstract}

Recommended for publication by Commission IX - Behaviour of Metals Subjected to Welding

Pauli Lehto

pauli.lehto@aalto.fi

1 Department of Mechanical Engineering, School of Engineering, Aalto University, P.O. Box 12200, FIN-00076 Aalto, Finland
Keywords (IIW Thesaurus) Grain size · Measurement · Structural steels $\cdot$ Hardness $\cdot$ Microstructure $\cdot$ Weld metal

\section{Introduction}

Microstructural characterisation of engineering materials is a necessity for understanding the relationships between microstructural quantities and mechanical properties. Grain size is one of the fundamental microstructural quantities and correlates with several properties, such as hardness, stress-strain curve and fatigue strength [1-7]. Based on the work of Hall [8] and Petch [9], a relationship was found between grain size and the mechanical properties of steel. For yield strength, this relationship is:

$\sigma=\sigma_{0}+k d^{-1 / 2}$

where $\sigma_{0}$ is the lattice friction stress required to move individual dislocations, $k$ is a material-dependent constant known as the Hall-Petch slope, and $d$ is the average grain size [10]. As the Hall-Petch relationship is related to the measure of grain size, the correct definition of grain size is crucial.

The most commonly reported microstructural measure in literature is the average grain, even though there is a large variety of, e.g. ASTM grain size measurement methods, available [11]. Moreover, orientation imaging microscopy gives the operator a large degree of freedom for defining the measurement methodology and parameters such as step size, grain boundary misorientation criteria and filtering of the data [12-14]. For these reasons, an extensive interlaboratory round-robin [15] was carried out in order to define the grain size measurement methodology for the ISO 13067 [16] standard. In addition to measurement of average grain size, other material-specific factors such as differences in phase structure and grain size distribution need to be considered. 
For heterogeneous materials, the grain size distribution is of particular interest since it has been shown to influence the mechanical properties [10, 17-22]. Improved grain size measurement methods are thus required to enhance the understanding between grain size distribution and mechanical properties [11]. Accurate description of the microstructural heterogeneity is also required for the mesoscale modelling of material behaviour [12]. Welds are an extreme case of heterogeneity since it is present both in macroscopic scale across the joint and in microscopic scale within a single zone; see Fig. 1. The grain size characterisation of heterogeneous weld metals was studied by Lehto et al. [23]. The grain size measurements revealed that structural steel weld metals exhibit a large variety of grain size distributions that are noticeably broader than those of the base metal. To capture the influence of grain size distribution, the volume-weighted grain size measurement was utilised. It was shown that the Hall-Petch relationship's dependence on grain size distribution is eliminated when then volume-weighted average grain size $\left(d_{v}\right)$ is used:

$\sigma=\sigma_{0}+k d_{v}^{-1 / 2}=\sigma_{0}+k d^{-1 / 2}\left(1+f \frac{\Delta d}{d}\right)$,

where $f$ is a constant describing the relation between average and volume-weighted average grain size and $\Delta d / d$ is the relative grain size dispersion. The equation is reduced to the original Hall-Petch Eq. (1) in the theoretical case that all grains are the same size. Furthermore, if samples with similar grain size dispersion are compared the original Hall-Petch, Eq (1) is applicable.

While the previous work covered the microstructural characterisation of volume-weighted average grain size and its relation to the grain size distribution of welded structural steel, it did not provide further insight into the inherent large local variation of grain size. The aim of this paper is to characterise the local variation of grain size in welded joints and investigate how it influences the mechanical properties using hardness measurements. The point-sampled grain size measurement method is extended for the characterisation of local grain size variation both in numerical and visual form. The numerical approach is to present a moving average of grain size using line probes in different directions. In visual approach, the characterisation of grain size variation is further developed by substituting grain size $(d)$ with the Hall-Petch grain size parameter $\left(d^{0.5}\right)$ in order to have a linear scale for grain sizedependent mechanical properties. The local variation of grain size is also compared to hardness measurement results.

\section{Measurement of local grain size variation}

Grain size is measured using the point-sampled intercept length method [24, 25]. The method is similar to the commonly used linear intercept method [26]; however, the measurements are carried out at random points instead of being measured along pre-determined lines. The method has previously been used for the characterisation of grain size distribution in welded structural steel [23]. Here, the method is extended for the characterisation of local grain size variation by including measurement direction-based averaging. In addition, moving averages of grain size are calculated across the microstructure. Figure 2 shows a flow chart of the measurement procedure using a fictional single-phase microstructure. Firstly, the grain size is measured for individual grains at random points that hit the grain interior (Fig. 2 (Ia)). The procedure is repeated a large number of times for one measurement direction, resulting in densely measured grain size for the individual grain (Fig. 2 (Ib)).
Fig. 1 Macro section of an arc welded joint (CV.1) and an example of weld metal grain size variation showing fine grained (FG) and coarse grained (CG) areas

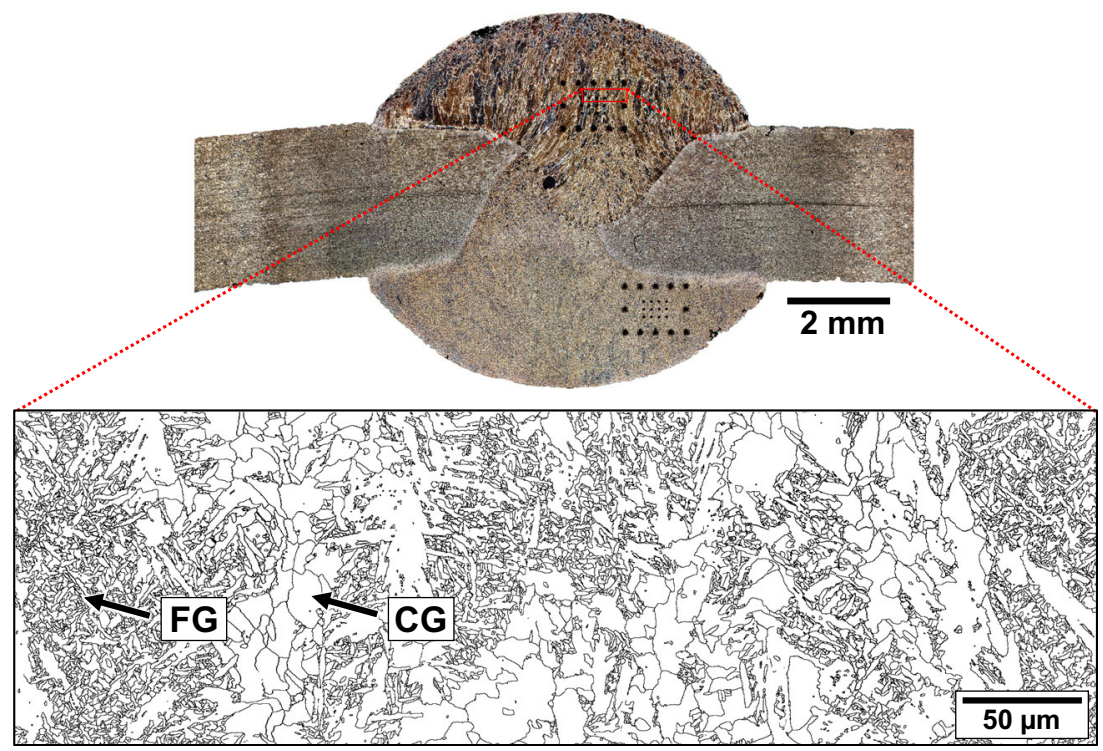


Fig. 2 Flowchart of the grain size measurement and analysis procedure
I) Grain size measurement using point-sampled linear intercept method

\begin{tabular}{c}
$\begin{array}{c}\text { I a) Linear intercept } \\
\text { at random points for } \\
\text { one grain }\end{array} \rightarrow \begin{array}{c}\text { I b) Horizontal grain } \\
\text { size at random } \\
\text { points }\end{array} \rightarrow \begin{array}{c}\text { Ic) Nearest neighbour } \\
\text { interpolation for better } \\
\text { visualisation }\end{array}$ \\
\hline
\end{tabular}

$\downarrow$

II) Procedure I repeated for all grains in four measurement directions

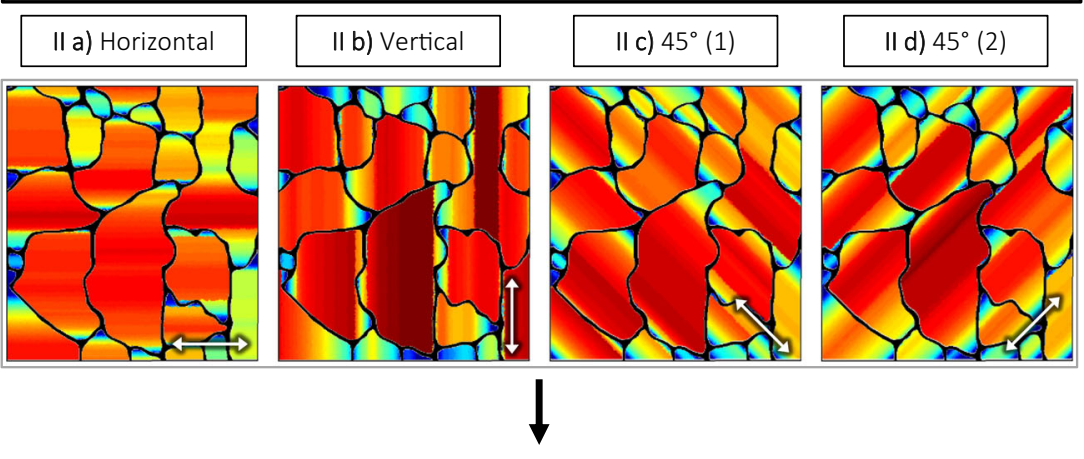

III) Combination of four measurement directions

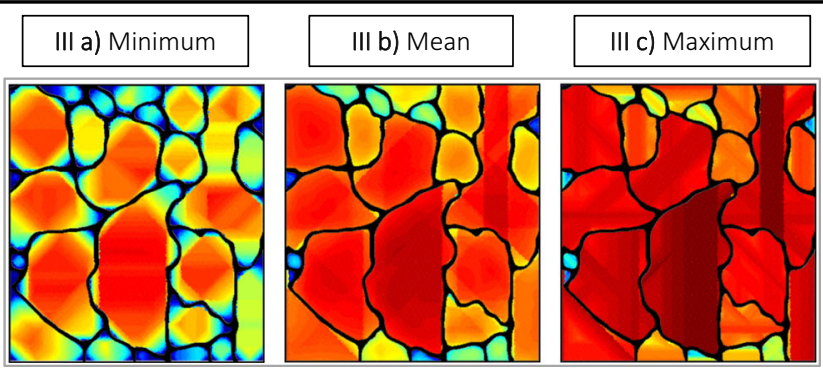

For an improved visual representation, the non-measured points are filled with a value from the nearest neighbouring point. As shown in (Fig. 2 (Ic)), the interpolation results in a good visual representation of grain size for the individual grain. Grain size is presented using the Hall-Petch grain size parameter $\left(d^{-0.5}\right)$ in order to have a linear scale for grain size affected mechanical properties. This approach is taken to improve the resolution of visual representation in the grain size regime below $10 \mu \mathrm{m}$. Based on the Hall-Petch relationship, a small change of grain size in this regime has a significant effect on the mechanical properties, e.g. strength doubles as grain size decreases from 4 to $1 \mu \mathrm{m}$; see Fig. 3. It is noted that the classical Hall-Petch relationship is applicable at grain sizes larger than $0.1 \mu \mathrm{m}\left(d^{-0.5}<3.16 \mu \mathrm{m}^{-0.5}\right)[27,28]$.

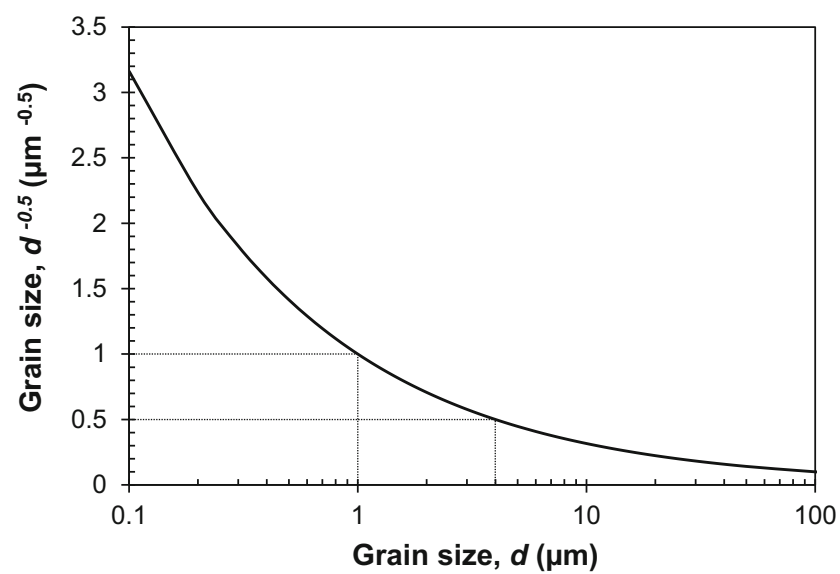

Fig. 3 Relationship between grain size $(d)$ and the Hall-Petch grain size parameter $\left(d^{0.5}\right)$ 
The procedures (Fig. $2(\mathrm{Ia}-\mathrm{c})$ ) are repeated for all grains in the fictitious microstructure using four measurement directions $\left(0^{\circ}, 45^{\circ}, 90^{\circ}\right.$, and $\left.135^{\circ}\right)$ as shown in Fig. 2 (IIa-d). Typically, at least $25 \%$ of the image points should be measured in each direction for accurate results. The probability $P_{i}$ of a random point hitting a grain of size $i$ is proportional to the surface area fraction of the grain. Based on relationships of stereology $[29,30]$, the surface area fraction provides a statistical estimator for the volume fraction:

$P_{i}=\frac{A_{i}}{A_{T}} \approx \frac{V_{i}}{V_{T}}$,

where $A_{i}$ and $V_{i}$ are the surface area and volume of a grain of size i. $A_{T}$ and $V_{T}$ are the total surface area and volume of all grains in the measurement domain, correspondingly. Thus, the measured grain size distribution can be considered as the volume-weighted grain size distribution if the assumption of isotropy is made. For further details and a Matlab implementation of the measurement procedure, the reader is referred to $[23,31]$.

To verify that the nearest neighbour interpolation does not introduce any bias or error to the data, the grain size distributions of the measured and interpolated data are compared in Fig. 4a. As the two counterparts overlap for each individual measurement direction, the interpolated data shown in (Fig. 2 (IIa-d)) can be used for further data analysis.

In order to compare grain size with mechanical properties, e.g. hardness, the four measurement directions need to be combined into a single visualisation. The three alternatives used are to take the minimum, mean or maximum value of the four measurement directions at each point of all grains; see in Fig. 2 (IIIa-c). As shown in Fig. 4b, the grain size distributions of minimum and maximum cases are the lower and upper bounds for the measurement data, respectively. The mean has closely the same volume- weighted average grain size, $d_{v}$ as the measurement data even though the shape of the distribution is different. The agreement of volume-weighted average grain size has been verified for various heterogeneous microstructures, with the error typically being smaller than $1 \%$. Since the volume-weighted average grain size has been shown to correlate with hardness according to the HallPetch relationship [23], the mean grain size plot is used for further result analysis of hardness and grain size.

In addition to the above mentioned visual options, the moving averages of the minimum, mean and maximum grain size contours (Fig. 2 (IIIa-c)) are calculated across the micrograph using horizontal and vertical line probes. The line probes used in this study are 10-pixel wide. In addition, the border regions of the micrographs were excluded from the averaging to eliminate large grains that extend beyond the micrograph. Grain size at $90 \%$ probability level was found as a suitable margin for exclusion at all edges of the image. Dimensions of the probes used are shown in Table 3. The difference between the three moving averages represents the local variation of grain size in different measurement directions.

\section{Experiments}

\subsection{Test specimens and sample preparation}

The experiments are carried out for one base metal (BM.1) and two welded samples. The weld samples are flux-core arc welded either from two sides (CV.1) or from one side with a ceramic backing (CV.2). Plate edges were prepared by plasma cutting followed by grinding. The energy input for CV.1 is $3.5 \mathrm{~kJ} / \mathrm{cm}$ for each side and for $\mathrm{CV} .2$ it is $9 \mathrm{~kJ} / \mathrm{cm}$ for the single weld bead. The macro sections of the weld samples CV.1 and


Fig. 4 Cumulative probability distributions for grain size (a) measured and interpolated data for the four measurement directions (see Ib, Ic and II in Fig. 2). b Comparison of the analysed (see III in Fig. 2) and measurement data 
Table 1 Test sample base metal grades and mechanical properties [23]

\begin{tabular}{llllll}
\hline & Grade & Thickness $(\mathrm{mm})$ & $R_{E H}(\mathrm{MPa})$ & $R_{m}(\mathrm{MPa})$ & $\mathrm{A}(\%)$ \\
\hline BM.1 & GL D36 & 6 & 343 & 472 & 34 \\
CV.1 & S355J2 & 3 & 466 & 564 & 31.3 \\
CV.2 & S355J2 & 3 & 466 & 564 & 31.3 \\
\hline
\end{tabular}

CV.2 are shown in Figs. 1 and 5, correspondingly. All base metals are S355 grade ferritic-pearlitic structural steels; the base metal grades and mechanical properties are presented in Table 1.

For this investigation, specimens are prepared from the base metal BM.1 and the two weld metals. To represent the extremities of the grain size distribution, two weld metal regions are chosen with homogeneous and heterogeneous grain size distributions. The root side weld metal of weld sample CV.1 is taken as the homogeneous weld metal, while the toe side weld metal of weld sample CV.2 is the heterogeneous weld metal. The three specimens are chosen since they have previously been found to closely follow the same relationship between grain size and hardness in the macroscopic scale using 70-100 $\mu \mathrm{m}$ hardness indentations [23]. The previously measured average hardness and grain size values, as well as phase volume fractions are presented in Table 2. The microstructural constituents were identified according to IIW document IX-1533-88 [32] by using the systematic manual point counting method according to ASTM E562-02 [33].

For the weld sample CV.2, an additional sample was prepared for EBSD analysis. The sample is used for comparing the grain size and hardness from the exact same location for the heterogeneous weld metal. This location is referred to as A2 in further instances. The location of this area and the hardness measurements carried out for the heterogeneous weld metal are shown in Fig. 5. All specimens were mounted in an electrically conductive resin and grinded up to P4000 grit abrasive paper. Polishing was done with 3 and $1 \mu \mathrm{m}$ diamond paste and the additional heterogeneous sample with $0.25 \mu \mathrm{m}$ as well. Before EBSD analysis, final polishing was carried out with colloidal silica in a vibratory polisher for $45 \mathrm{~min}$.

\subsection{Material characterisation}

Instrumented indentation testing was used for measuring the mechanical properties. Hardness was measured with a CSM Instruments micro-indentation tester according to ISO $14577-$ 1 [34] utilising large matrices containing up to 200 indentations. Hardness was defined using Martens hardness, denoted by $H M$, with a Vickers pyramid tip. The measurement data related to, but not presented in [23], indicates that $H M$ correlates well with traditional Vickers hardness when presented in the same units; see Appendix 1 for further details. The test

Table 2 Test specimen nomenclature, microstructural characterisation and the microstructural constituent volume fractions and the corresponding $95 \%$ confidence intervals [23]

\begin{tabular}{|c|c|c|c|c|c|c|}
\hline & \multirow[t]{2}{*}{ Sample } & \multirow{2}{*}{$\begin{array}{l}\text { Grain size } \\
d_{v}(\mu \mathrm{m})\end{array}$} & \multirow{2}{*}{$\begin{array}{l}\text { Hardness } \\
\mathrm{HM}(\mathrm{MPa})\end{array}$} & \multicolumn{3}{|c|}{ Constituent volume fraction $(\%)$} \\
\hline & & & & $\mathrm{AF}$ & $\mathrm{PF}$ & $\mathrm{FC} / \mathrm{P}$ \\
\hline Base metal & BM.1 & $15.29 \pm 1.96$ & $1412 \pm 29$ & - & $78.6 \pm 5.3$ & $21.4 \pm 5.3(\mathrm{P})$ \\
\hline Homogeneous weld metal & CV.1 root & $5.95 \pm 0.20$ & $1756 \pm 17$ & $7.3 \pm 1.4$ & $78.7 \pm 4.7$ & $14.0 \pm 3.4$ \\
\hline Heterogeneous weld metal & CV.2 toe & $4.00 \pm 0.45$ & $1984 \pm 34$ & $37.5 \pm 6.4$ & $56.2 \pm 5.3$ & $6.3 \pm 1.6$ \\
\hline
\end{tabular}

Abbreviations used: $d_{v}$ volume-weighted average grain size, $H M$ Martens hardness, $P F$ primary ferrite, $A F$ acicular ferrite, $F C$ ferrite-carbide aggregate, $P$ pearlite [23]
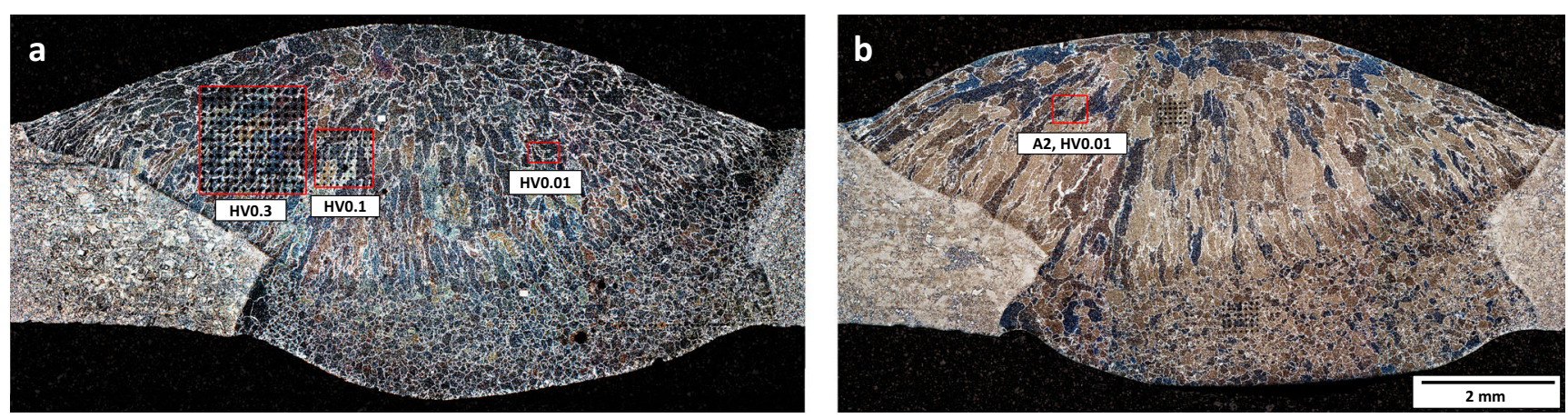

Fig. 5 Two macro sections of the arc welded joint CV.2 showing the hardness measurement locations of the heterogeneous weld metal presented in a Fig. 11 and b Fig. 12 

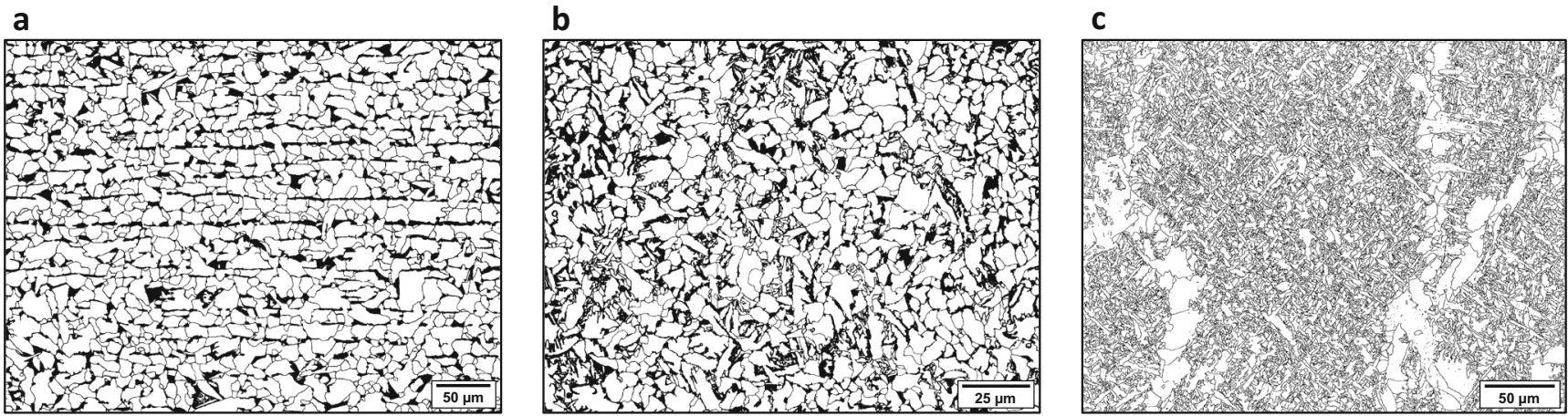

Fig. 6 The grain boundary maps used for grain size analysis of a base metal, $\mathbf{b}$ homogeneous weld metal and $\mathbf{c}$ heterogeneous weld metal

forces used equal HV0.01 $(98.07 \mathrm{mN}), \mathrm{HV} 0.1(980.7 \mathrm{mN})$ and HV0.3 $(2942.1 \mathrm{mN})$, producing indentations with approximately 7-10 $\mu \mathrm{m}, 30-35 \mu \mathrm{m}$ and 50-60 $\mu \mathrm{m}$ diagonal lengths, respectively, depending on the sample. Indentation depth is approximately $1 / 7$ th of the indentation diagonal, i.e. $1-$ $1.4 \mu \mathrm{m}, 4.3-5 \mu \mathrm{m}$ and $7.1-8.5 \mu \mathrm{m}$ for the three measurement forces, respectively. Linear 30-s loading ramps were used, with a hold time of $10 \mathrm{~s}$ at the maximum force.

The heterogeneous microstructure was characterised using the electron backscatter diffraction (EBSD). EBSD analysis of the heterogeneous weld metal in sample CV.2 (location A2) was carried out prior to hardness measurements at a premarked area. A Zeiss Ultra 55 field emission scanning electron microscope equipped with a Nordlys F+ camera and Channel 5 software from Oxford Instruments was used for the EBSD analyses. The EBSD analyses were performed with a step size of $0.2 \mu \mathrm{m}$ at a magnification of $1000 \times$ (area $373 \times 280 \mu \mathrm{m}$ ). The acceleration voltage was $20 \mathrm{kV}$ and the grain boundary misorientation criteria of $10^{\circ}$ were used. Indexing rate of the EBSD maps was approximately $90 \%$ and the EBSD data was post-processed using a nearest neighbour clean-up routine. The grain boundary maps from EBSD analysis were overlaid on optical micrographs and digital image processing applied in order to de-skew the distortions caused by stage drift during acquisition [35]. For optical micrographs, the samples were etched with a $2 \%$ Nital solution. Digital image processing was carried out to create grain boundary maps from the optical micrographs for base metal and homogeneous weld metal; see [31] for more details.

\section{Results}

\subsection{Microstructure and grain size}

The microstructures of the three specimens are shown in Fig. 6 . The measured average grain sizes $\left(d, d_{v}\right)$ of the single micrographs and the dimensions of the averaging line probes are presented in Table 3. The line probes are 10-pixel wide and thus the magnification of the micrograph affects the width of the probe. The relative grain size dispersion values for the three specimens are defined based on [23]:

$\frac{\Delta d}{d}=\frac{d_{\max }-d_{\min }}{d}=\frac{d_{99 \%}-d_{1 \%}}{d}$,

where the maximum and minimum grain sizes are taken as 99 and $1 \%$ probability level grain sizes, respectively. This value characterises the grain size dispersion on a macroscopic scale for the entire micrograph, see Ref [23] for further details.

The local grain size variation found in base metal as well as homogeneous and heterogeneous weld metals are compared in Fig. 7. Base metal and homogeneous weld metal have quite homogeneous grain size as is indicated by the relative grain size dispersion. The local variation of grain size is not significant and moreover the local variation is homogeneous throughout the microstructure. On the contrary, local variation of grain size is significant for the heterogeneous weld metal. The coarse-grained areas have inconsistent spacing as shown in Fig. $7 \mathrm{c}$, and thus one grain boundary map of size

Table 3 Measured average grain sizes for the three microstructures presented in Fig. 6 and dimensions of the line probes used for grain size averaging

\begin{tabular}{|c|c|c|c|c|c|c|c|c|}
\hline & \multicolumn{3}{|c|}{ Grain size } & \multicolumn{3}{|c|}{ Line probe dimensions } & \multicolumn{2}{|c|}{ Grains per line length } \\
\hline & $d(\mu \mathrm{m})$ & $\Delta d / d(-)$ & $d_{v}(\mu \mathrm{m})$ & Line width $(\mu \mathrm{m})$ & Horizontal $(\mu \mathrm{m})$ & Vertical $(\mu \mathrm{m})$ & Horizontal (-) & Vertical (-) \\
\hline Base metal & 10.18 & 3.16 & 15.43 & 1.84 & 532 & 385 & 35 & 25 \\
\hline Homogeneous weld & 3.47 & 3.60 & 5.94 & 0.74 & 213 & 154 & 36 & 26 \\
\hline Heterogeneous weld & 2.21 & 5.38 & 5.01 & 0.98 & 321 & 241 & 64 & 48 \\
\hline
\end{tabular}

Grains per line length is defined as line length divided by the volume-weighted average grain size 

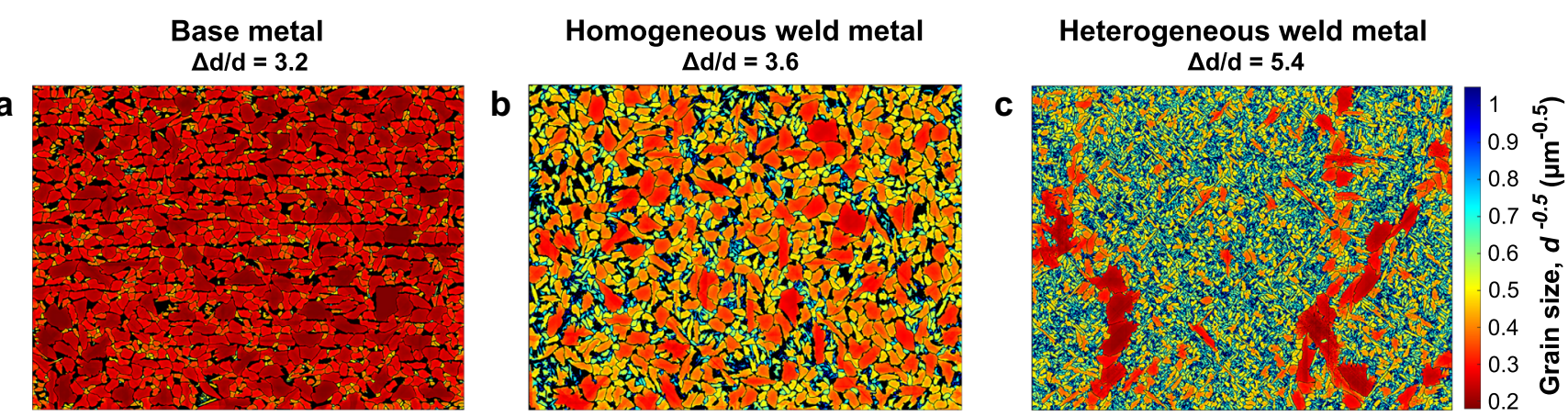

Fig. 7 Comparison of local grain size variation for S355 base metal, homogeneous and heterogeneous weld metals. The colour contours range between 0.18 and $1.05 \mu \mathrm{m}^{-0.5}$, representing the largest $99 \%$ and smallest $1 \%$ probability level grain sizes for the three specimens

$345 \times 266 \mu \mathrm{m}$ does not fully represent the length scale at which the coarse and fine-grained areas alternate.

\subsection{Characterisation of the local grain size variation}

The local grain size variation of base metal, homogeneous weld metal and heterogeneous weld metal is shown in Figs. 8, 9, and 10 , correspondingly. The dimensions of the line probes used for the calculation of moving averages are presented in Table 3. It can be seen that the grain size of the base metal (Fig. 8) is very uniform when the mechanical properties are considered on grain scale according to the Hall-Petch relationship $\left(d^{-0.5}\right)$. Variation around the volume-weighted average grain size $\left(d_{v}\right)$ is minor for the moving average of the mean grain size. In terms

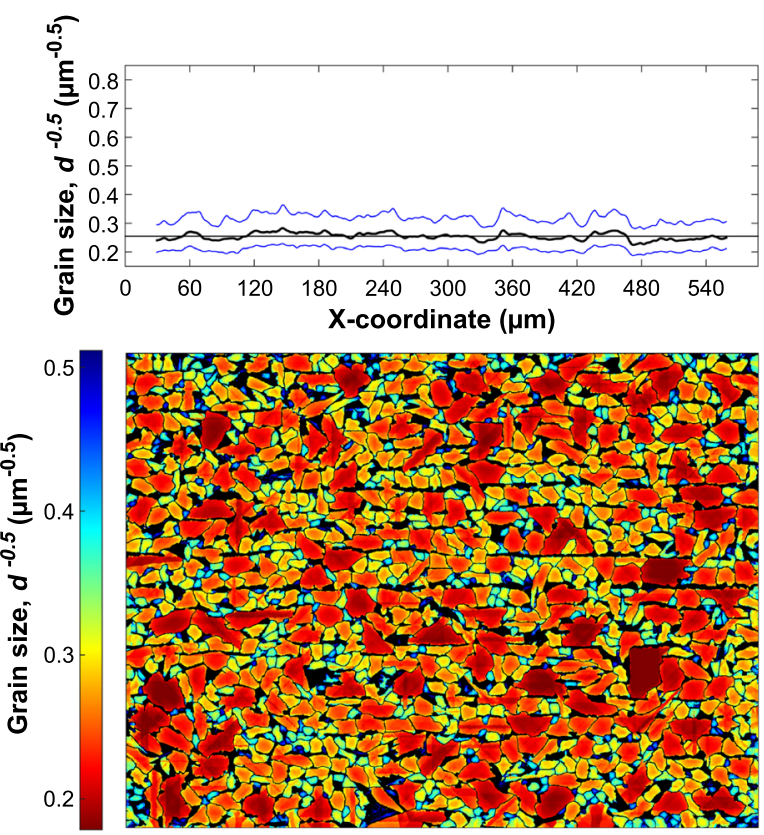

Fig. 8 Grain size plotted as a function of the Hall-Petch grain size parameter $\left(d^{0.5}\right)$ for the base metal (S355). The colour contour ranges from 99 to $1 \%$ probability level grain size for the main figure. The colour of grain size, it is difficult to find strong or weak locations in the microstructure as the smallest and largest grains are within a narrow band of approximately $0.2-0.5 \mu \mathrm{m}^{-0.5}$. For homogeneous weld metal (Fig. 9), the variation of grain size is very similar to base metal, with little variation around the volumeweighted average grain size. Relatively, the minimum and maximum are further away from the mean curve, which is related to the broader grain size dispersion compared to base metal. This is visible as an increased amount of fine grains (acicular ferrite, $A F)$ in between the coarse grains (primary ferrite, $P F$ ). For heterogeneous weld metal (Fig. 10), the location of coarse grains can be determined both visually and using the horizontal moving average of grain size. The areas with coarse grains are primary ferrite while fine-grained areas consist mostly of



contour range is extended for the side figures to cover the 1 and $99 \%$ probability level grain sizes of the minimum and maximum cases 

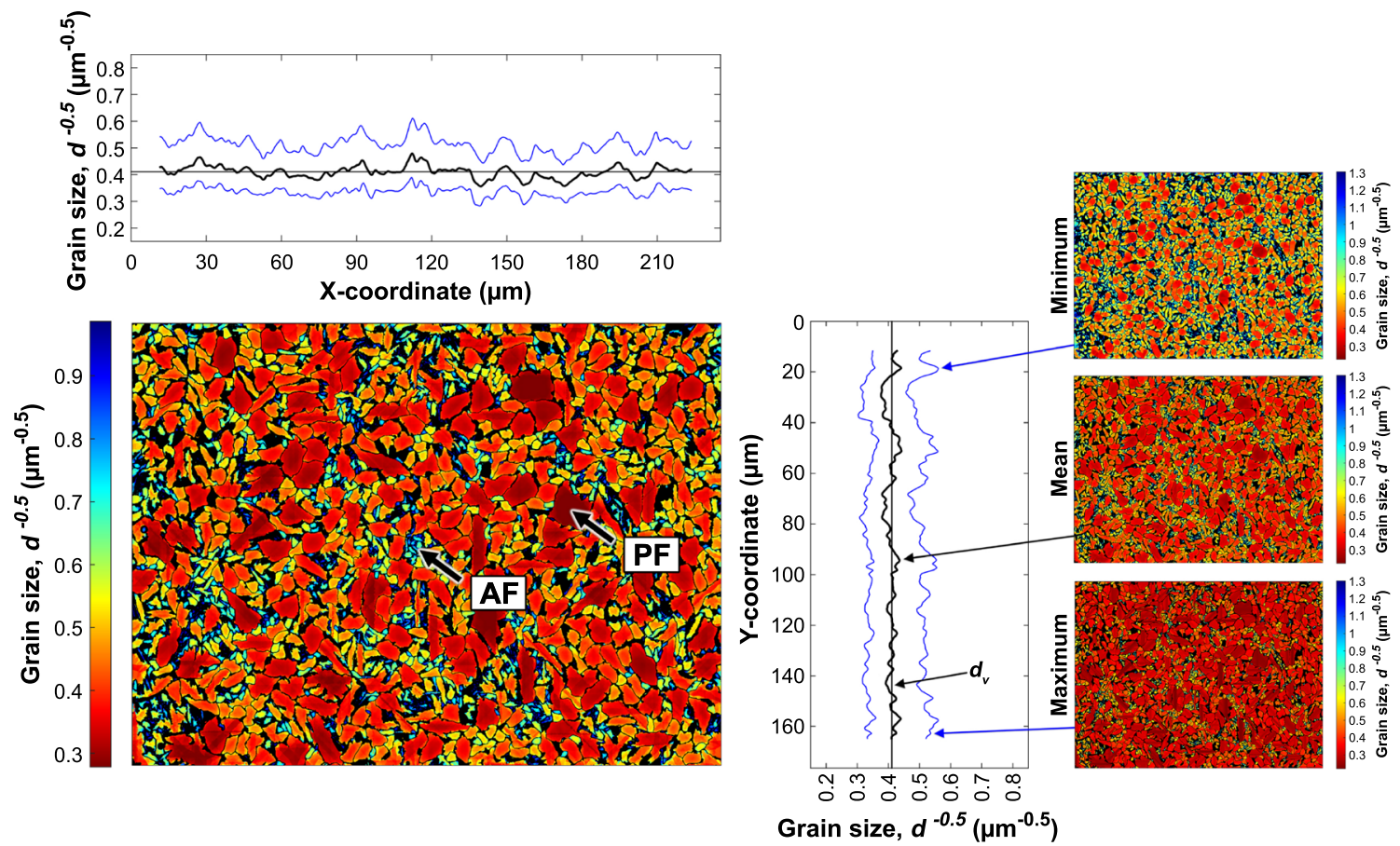

Fig. 9 Grain size plotted as a function of the Hall-Petch grain size parameter $\left(d^{-0.5}\right)$ for the homogeneous weld metal. The colour contour ranges from 99 to $1 \%$ probability level grain size for the main figure. The

acicular ferrite. Furthermore, there is also noticeable grain size variation within acicular ferrite. Of the three specimens, the difference between minimum and maximum moving averages

colour contour range is extended for the side figures to cover the 1 and $99 \%$ probability level grain sizes of the minimum and maximum cases

is largest for the heterogeneous weld metal in the area that consists primarily of acicular ferrite (X-coordinate 100 $200 \mu \mathrm{m})$
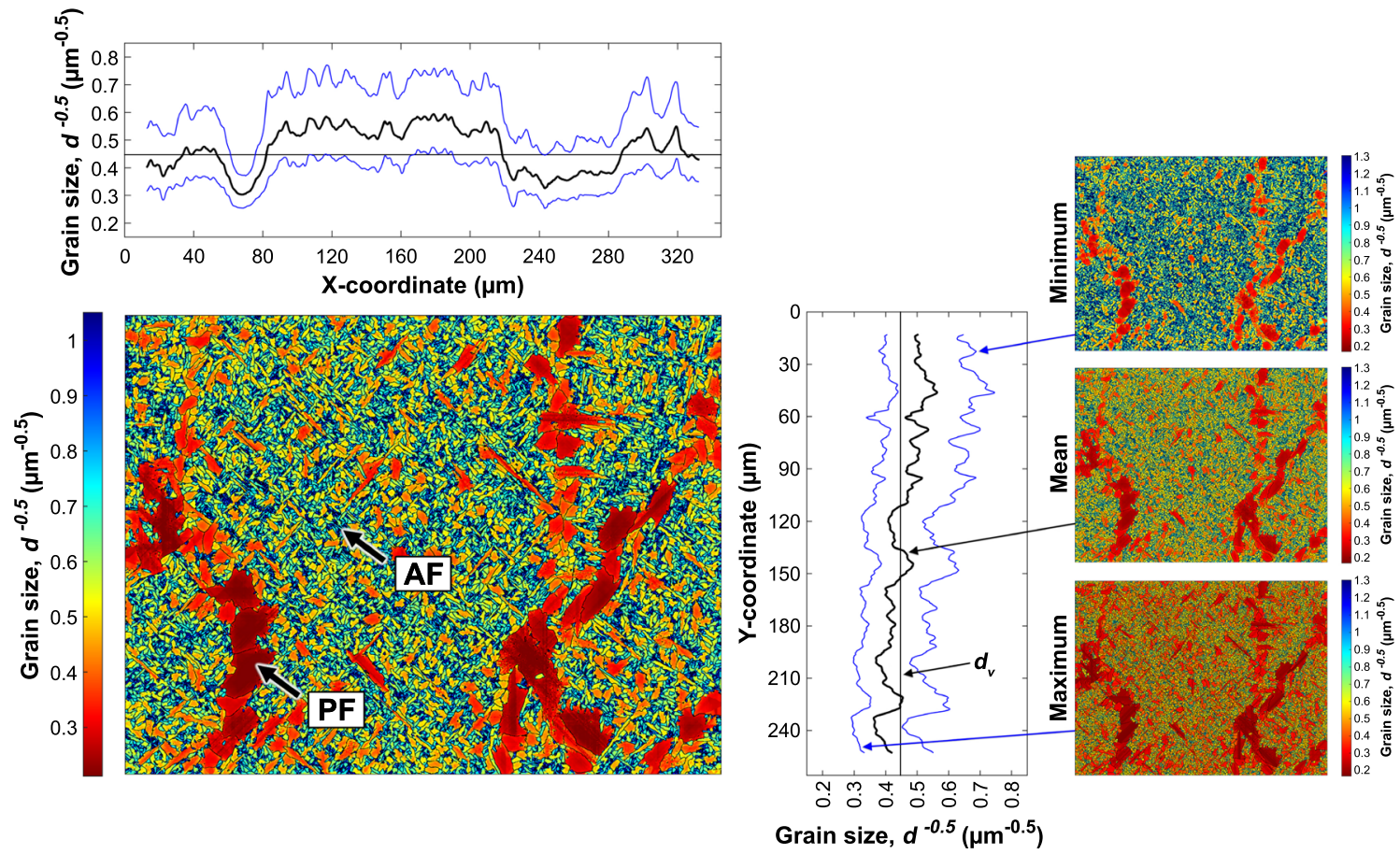

Fig. 10 Grain size plotted as a function of the Hall-Petch grain size parameter $\left(d^{0.5}\right)$ for the heterogeneous weld metal. The colour contour colour contour range is extended for the side figures to cover the 1 and $99 \%$ probability level grain sizes of the minimum and maximum cases 
4.3 Comparison of hardness variation in $\mathrm{S355}$ base metal and weld metal

The variation in grain size indicates that the mechanical properties might also vary significantly within the heterogeneous microstructure. The local variation in hardness measured using test forces HV0.01, HV0.1 and HV0.3 is shown in Fig. 11. The diagonal lengths of the indentations are approximately 7-10 $\mu \mathrm{m}, 30-35 \mu \mathrm{m}$ and 50-60 $\mu \mathrm{m}$, respectively. For clarity, the grain size comparison presented in Fig. 7 is from the same specimens but not at the exact location of the hardness measurements. Hardness is presented as an interpolated colour contour, and thus, it should be noted that the values in between the indentations do not represent real hardness values.

For all specimens, it is observed that the mean hardness value increases with a decrease in indentation size. At the same time, the maximum hardness values increase significantly while minimum values remain approximately the same. Using the smallest test force of HV0.01, the difference between lowest and highest measured hardness values is significant, up to 0.9 times the


Homogeneous weld metal $\Delta d / d=3.6$

d



e

Heterogeneous weld metal $\Delta d / d=5.4$

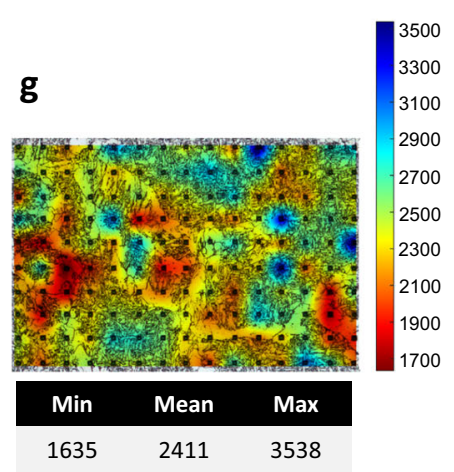

h
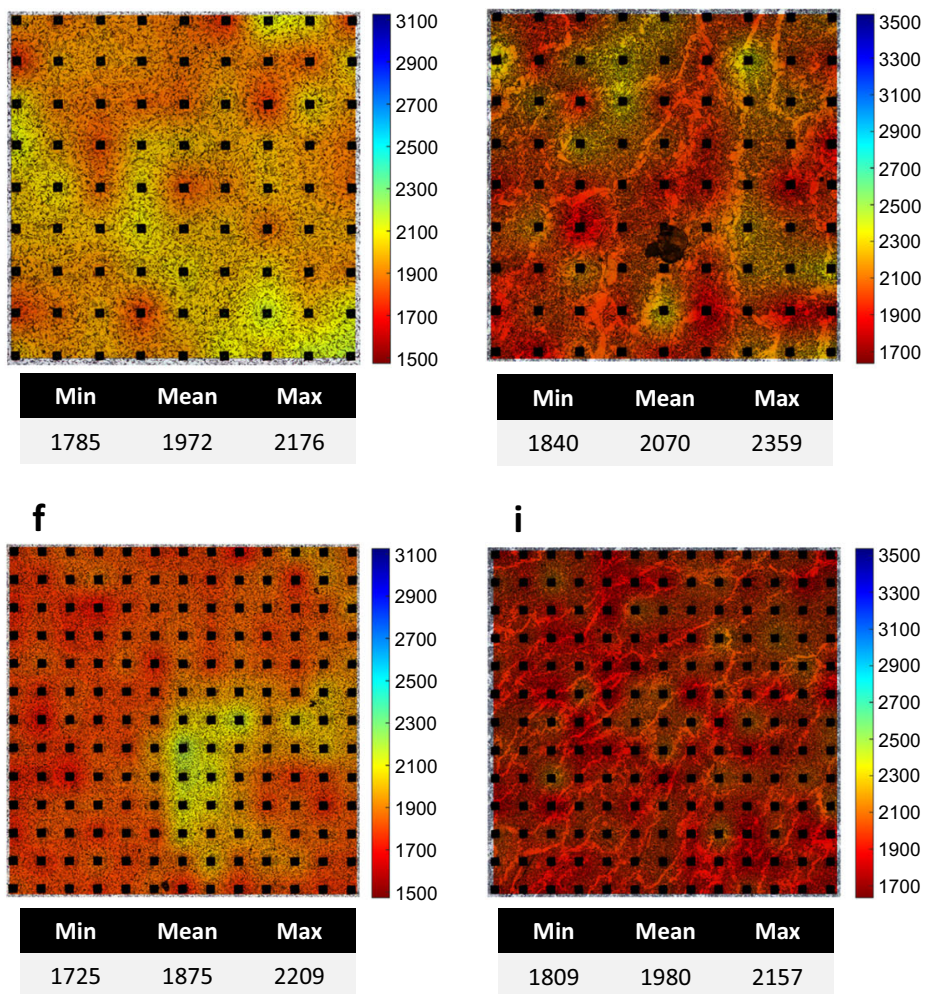

i



Fig. 11 Comparison of local hardness variation $(H M)$ using three different indentation loads for the three specimens. The colour scales range between HV0.01 minimum and maximum for each specimen 
average value. This can be related to the placement of the small indentations in the microstructure, hitting e.g. entirely in soft ferrite grain interiors or hard pearlite.

While base metal and homogeneous weld metal generally show smooth transitions between low and high hardness areas, the heterogeneous weld metal shows much higher local variation. This is the case particularly for the HV0.01 measurement force that produces small, 7-10 $\mu \mathrm{m}$ indentations. At higher test forces of HV0.1 and HV0.3, base metal and homogeneous weld metal show variation in hardness even though the grain size is very uniform in the structure. Likewise, with HV0.3 indentations, the local variation in hardness cannot be captured for the heterogeneous weld metal since the indentations are larger than the coarse-grained areas. Thus, it is challenging to choose indentation parameters; indentation size in relation to grain size and at the same time the spacing of indentations affects the data gathered from a predetermined area. The transition and relations between different size indentations, as well as the relation to tensile properties require further study.

\subsection{Correlation between grain size and hardness}

To investigate the local grain size variation, additional hardness measurements were carried out for the heterogeneous weld metal. Prior to hardness measurements, an EBSD analysis was carried out at location A2 of the weld (see Fig. 5) that was pre-marked with hardness indentations. After hardness measurements, the specimen surface was etched, which enables overlaying of the EBSD maps on the microstructure and identifying the location of hardness indentations.

The hardness data and grain size contour for the studied heterogeneous weld metal are shown in Fig. 12. The figure contains (a) an optical micrograph of the hardness measurements, (b) visual estimate of correlation between hardness and local microstructure and (c) hardness in discrete form for individual indentations overlaid on the grain size contour. The visual estimate in (b) is divided into three categories: (1) green, grain size under the indentation correlates with hardness within approximately $\pm 100 H M(52 / 96$ samples, $54 \%$ ); (2) orange, hardness correlates with grain size when the microstructure surrounding the indentation is considered (18/96,
Fig. 12 a Optical micrograph of the hardness measurement area for the heterogeneous weld metal area $\mathrm{A} 2$, $\mathbf{b}$ grain boundary map and visual estimation of the correlation between local grain size and hardness; see text for the explanation and $\mathbf{c}$ the hardness value for each indentation overlaid on the grain size contour, ranging from 99 to $1 \%$ probability level grain size a
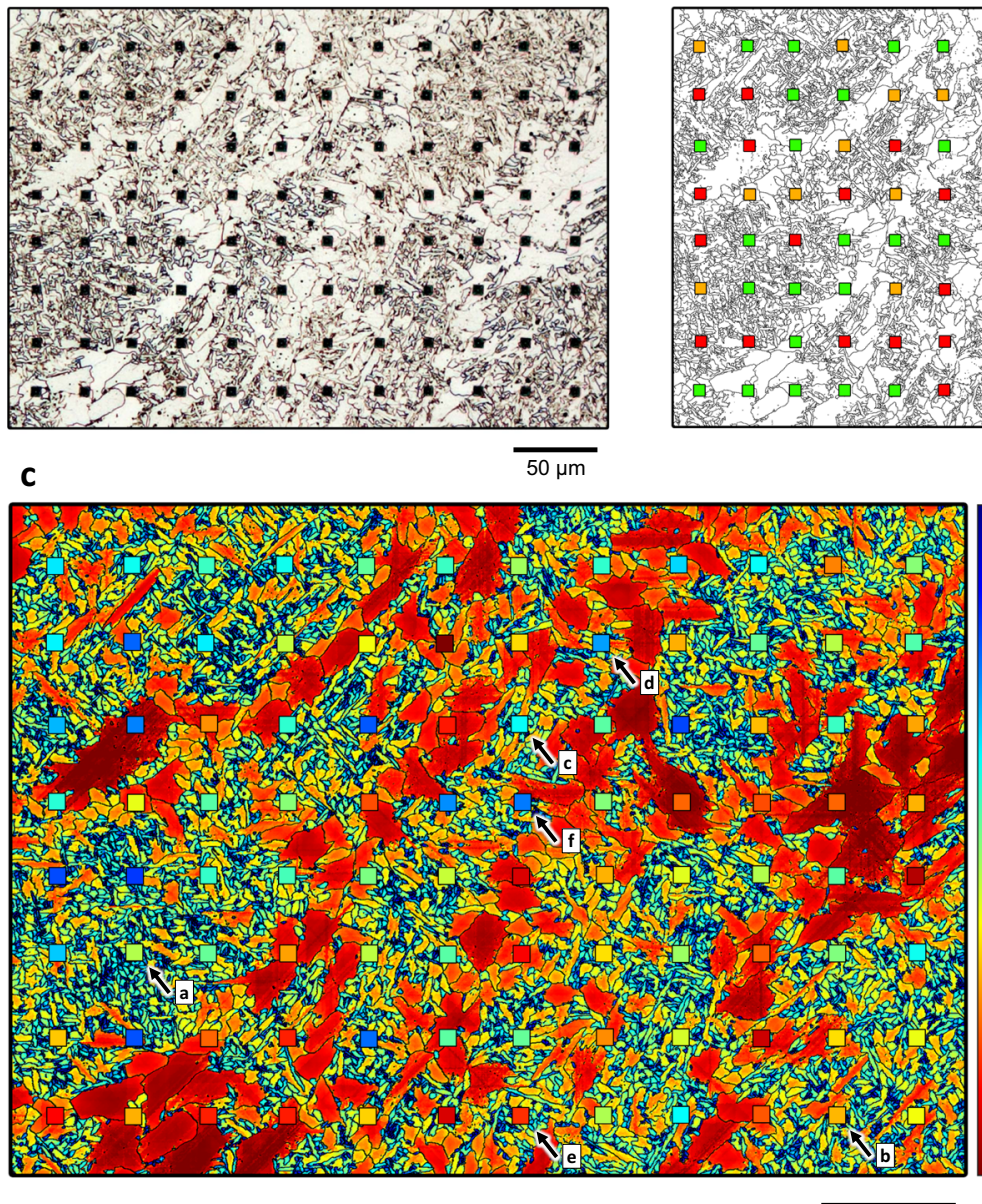

$50 \mu \mathrm{m}$ b


- 
$19 \%$ ) and (3) red, hardness and local grain size show no correlation (26/96, $27 \%$ ). Reader is referred to Appendix 2 for the hardness values and a figure that shows the grain size under and around each indentation.

In general, the low hardness areas correspond with the coarse grains and high hardness with the fine-grained areas. A mixture of different grain sizes under the indentation is found to result in a measured hardness value that corresponds approximately with the average grain size of the area according to the rule of mixtures; see Fig. 13a. When fine grains are surrounded by coarse grains, hardness is found to decrease, and in the opposite case, to increase; see Fig. 13b, c, correspondingly. Placement of the indentation tip in a small cluster of fine grains is found to increase the hardness value, even though the microstructure under and around the indentation would otherwise consist of coarse grains; see Fig. 13d. In some cases, low hardness is measured in fine grains and high hardness in coarse grains; see Fig. 13e, f, correspondingly. Further numerical analysis of the microstructure at each indentation is required before correlations between local microstructure and hardness can be formulated.

\section{Discussion}

The local grain size and hardness variation of ferritic base metal and two weld metals were studied. The point-sampled intercept length method was extended for the characterisation of local grain size variation. The local gradient of grain size variation and its dependency on measurement direction were considered. Base metal and homogeneous weld metal did not have significant local grain size variation, while the heterogeneous weld metal had distinct areas of coarse and fine grains. The coarse-grained areas are associated with primary ferrite and the fine-grained areas with acicular ferrite. Hardness was measured to investigate the influence of local grain size variation on mechanical properties.

EBSD grain size analysis is typically carried out using the grain identification and determination of grain size from its surface area, often taken as the diameter of a circle with an equivalent surface area $[12,36]$. For homogeneous equiaxed microstructures, this assumption is justified, and values determined by circle equivalent diameter $\left(d_{\text {ceq }}\right)$ and linear intercept are comparable within $10 \%$ of each other [15]. The use of circle equivalent diameter has limitations when applied to heterogeneous weld metal microstructures. Welds can have microstructures where definition of individual grains is ambiguous due to discontinuities in the grain boundaries, and thus clusters of multiple grains can be detected as a single grain. This has been demonstrated for stainless steel pipe welds by Saukkonen et al. [37], also showing the robustness of the linear intercept method to EBSD indexing errors and the consequent grain detection. Furthermore, the circle equivalent diameter is not well suited for high aspect ratio grains by itself, and more information about the shape of the grain is required [38]. For welds, the high aspect ratio of grains, as well as morphological anisotropy, make the assumption of circular geometry invalid. Thus, the volume-weighted linear intercept method should be preferred for grain size measurement of heterogeneous weld microstructures with complex grain morphologies. To that end, the methodology presented here is able to consider the aspect ratio of grains through the four measurement directions. Although limited to four measurement directions, it seems sufficient for the characterization of weld metal

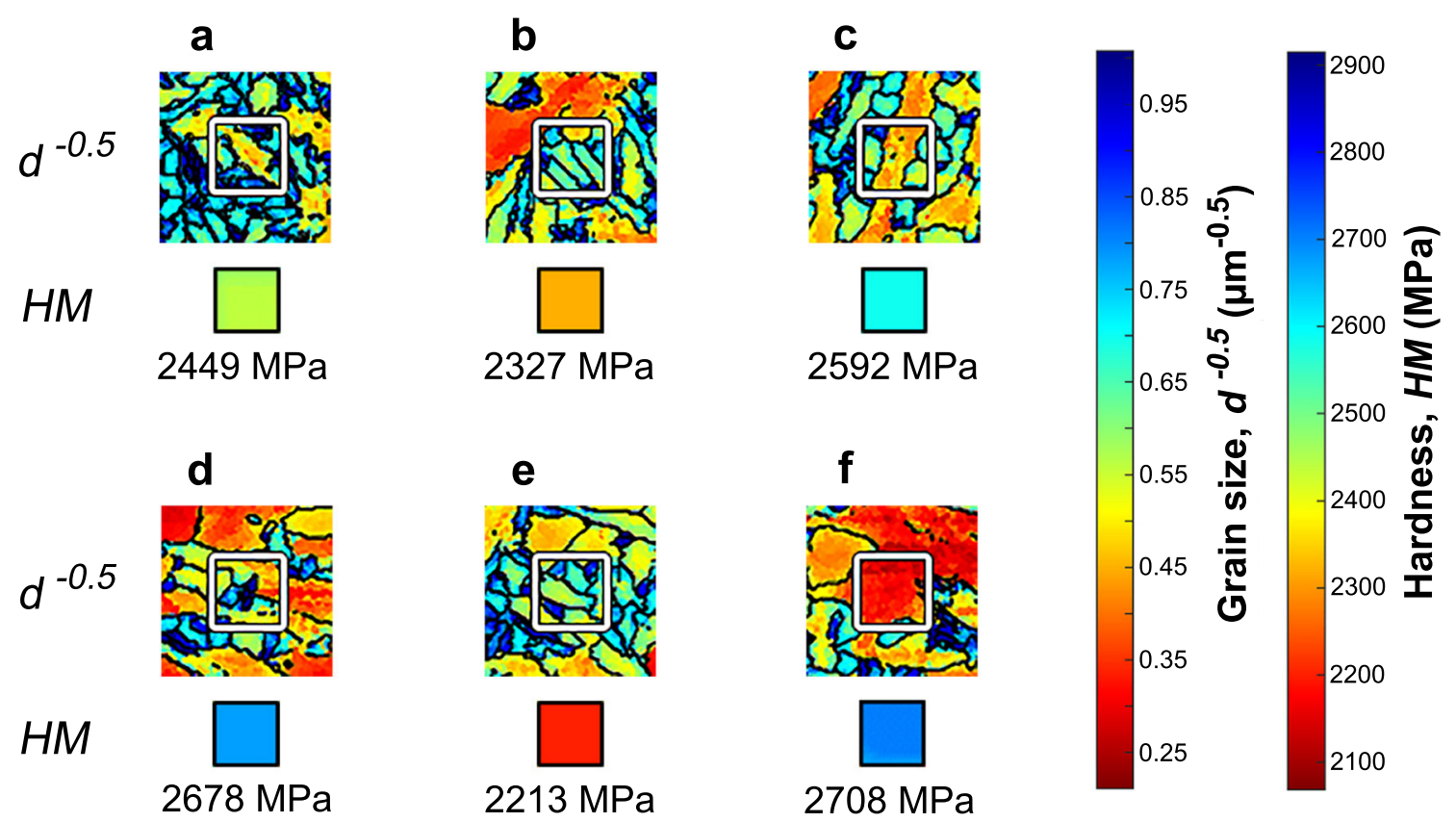

Fig. 13 Expanded view of grain size and hardness at indentations a-f indicated in Fig. 12c 
microstructures. It is also not sensitive to small discontinuities in the grain boundaries that are observed in welded [39, 40] and deformed [41] steel microstructures. For a physically based definition, the grain size measurement direction should be parallel with the direction of the slip plane in each grain, requiring the utilisation of orientation information in grain size measurement. As the present approach is based on measurement of 2D sections, the morphological anisotropy of the grains is not considered.

Grain size variation was found to be significant within acicular ferrite in the heterogeneous weld metal, having the biggest relative difference between the minimum and maximum grain size curves in Fig. 10. The variation is related to the high aspect ratio of the grains, resulting in a significant difference between the shortest and longest grain size measurement directions. Local variation of grain size is visually significant within acicular ferrite, as shown in Figs. 10 and 12c, ranging approximately between 1 and $5 \mu \mathrm{m}$ even though not revealed by the moving average line probe. The line probes are influenced by the number of grains falling under the line, and thus, the true variation will average out with a large number of grains. This is the case for acicular ferrite in the heterogeneous weld metal, and further research is required to define methods better suited for quantifying the local grain size variation numerically.

Even though the base metal and homogeneous weld metal are uniform in grain size, hardness measurements revealed low and high hardness regions using HV0.1 and HV0.3 test forces; see Fig. 11b, c, e and f. Visually, the grain size is uniform through the entire microstructure, and thus, it seems that factors other than grain size contributed to the observed differences. Hardness measurements using HV0.01 test force revealed that in the heterogeneous weld metal, the low hardness values are usually associated with coarse grains and high hardness values with fine grains, as is expected by the Hall-Petch relationship $[8,9]$; see Fig. 12c. Despite the visual estimate of $54 \%$ of hardness measurements corresponding with the local grain size (Fig. 12b), variation is observed between regions of similar grain size. This can be caused by differences in grain orientation [ [42, 43] and dislocation slip transmission between grains [44, 45].

The plastic zone from a hardness indentation is hemispheric, extending 1.0-1.9 times the contact radius with the highest plastic strain $(>20 \%)$ located directly underneath the indenter contact region [46]. Therefore, the microstructure of the entire plastic zone will influence the hardness measurement. This is visible for the $19 \%$ of measurements where surrounding coarse or fine grains either decreased or increased the hardness value, respectively. The limitation of observing grain size on the surface of the specimen is visible with $27 \%$ of the measurements as the grain size is not in agreement with the measured hardness value. Furthermore, the microstructural length scale, e.g. grain size, interacts with the length scale of hardness measurements [47]. These effects become relevant with indentations small relative to the grain size, and disappear as the length scale of deformation is large relative to the microstructural heterogeneities [47]. For the heterogeneous weld metal, the coarse grains are up to $25 \mu \mathrm{m}$ in size while the fine grains are $1-5 \mu \mathrm{m}$ in size, and thus the plastic zone of an indentation with $7-\mu \mathrm{m}$ diagonal and $1-\mu \mathrm{m}$ depth can be limited to a few grains or tens of grains. Therefore, the size of the plastic zone can vary depending on grain size and should be considered in the grain size measurement.

In addition to grain size characterisation, phase properties need to be considered in microstructural analysis. Even though in case of acicular ferrite and primary ferrite the phases behave similarly in hardness measurements [23], the tensile properties and toughness can show significant differences despite similarity of grain size. Zhao [48] found that acicular ferrite $(d=4-5 \mu \mathrm{m})$ had lower ultimate tensile strength but higher yield strength than ultrafine-grained ferrite $(d=1 \mu \mathrm{m})$. The differences were attributed to carbonitride precipitation, higher dislocation density and the lath bundle size of acicular ferrite. In general, acicular ferrite is beneficial for mechanical properties and besides tensile properties it improves impact toughness and decreases the transition temperature $[49,50]$. Thus, methods are sought after to increase the volume fraction of acicular ferrite in welds [49, 51].

In this study, the weld metal microstructures were examined using two dimensional analysis. Based on current analysis hardness shows good agreement (54\%) in locations where the local grain size gradient is typically small. It is expected that the gradient of grain size under the indentation has a significant effect on measured hardness values as well. It is likely that for the locations with good agreement the grain size gradient under the indentation is small or that the gradient is such that the measured hardness appears to correlate with surface grain size. For weld metals, the solidification behaviour controls the grain structure and the achieved mechanical properties [52]. The competitive growth of grains, influenced by the transient thermal conditions and solidification characteristics of the weld metal, determines the morphology of the grain structure $[52,53]$. In fusion welding axial, columnar and equiaxed grain morphologies can be observed depending on the thermal gradient, cooling rate and use of grain refining particles $[52,54$, 55]. Therefore, the appearance of the grains on one cross section may not be representative of the grain morphology [56], causing bias for the assumed relationship between surface area and volume (Eq. 3). For example, columnar grains can appear very large on the transverse section even though the grains are quite shallow. Thus, the morphology of the grains and the anisotropy of the microstructure in the direction of the weld bead should be included in the analysis. It is expected that hardness of the heterogeneous weld metal (Fig. 12) is better predicted if the morphological anisotropy is considered. Furthermore, other obstacles to dislocation motion such as inclusions can influence the measured hardness values on a local scale. Consideration of these aspects is left for future work. 


\section{Conclusions}

The point-sampled grain size measurement method was extended to the characterisation of local grain size variation. The Hall-Petch grain size parameter $\left(d^{0.5}\right)$ was found to give a good visual representation of grain size-dependent mechanical properties. Heterogeneous weld metal was found to have significant local variation of grain size while base metal and homogeneous weld metal were not. Furthermore, the local variation of grain size correlates with hardness measurements for a large portion of the measurements, with coarse grains generally showing low hardness and fine grains high hardness. Grain size alone was not able to explain all of the measurement results and thus future work is needed to analyse the local microstructure to determine factors other than grain size that should be included in the microstructural characterisation. In particular, the morphological anisotropy, i.e. the three dimensional shape of the grains needs to be characterized.

Acknowledgments The work has been done within the FIMECC BSA (Breakthrough Steels and Applications) programme as part of the FIMECC Breakthrough Materials Doctoral School. We gratefully acknowledge the financial support from the Finnish Funding Agency for Innovation (Tekes) and the participating companies. Funding from the Academy of Finland project "Fatigue of Steel Sandwich Panels" (FASA) under grant agreement no. 261286 is gratefully appreciated. The constructive comments of Professor Sven Bossuyt from Aalto University School of Engineering are gratefully acknowledged. Tuomo Nyyssönen from Tampere University of Technology is acknowledged for providing EBSD data suitable for the preliminary development of the grain size measurement Matlab code.

\section{Appendix 1: Vickers hardness compared to instrumented indentation hardness}

Traditional hardness measurements rely on measurement of, e.g. the diagonal of the indentation after the test force has been removed. As a result, only the residual plastic deformation is

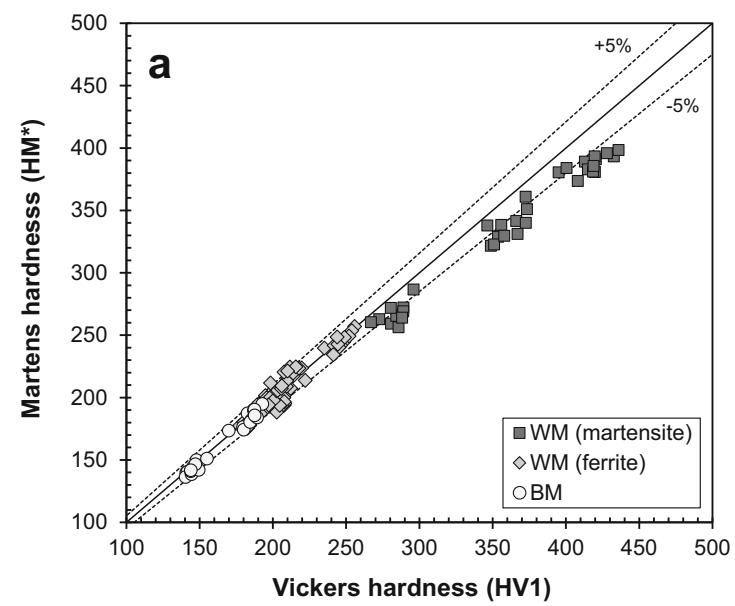

Fig. 14 Comparison of base metal (BM) and weld metal (WM) Vickers hardness (HV1) to a Martens hardness (HM) and $\mathbf{b}$ indentation hardness converted to Vickers hardness. The asterisk indicates conversion of units considered and elastic deformation is ignored. Instrumented indentation testing (IIT) enables the evaluation of both the elastic and plastic deformation by monitoring of the test force and displacement of the indenter. In addition to hardness, other material parameters such as indentation modulus can be determined without the need for optical measurement of the indentation [34].

Due to the force-displacement data being available, several definitions can be used for defining hardness from IIT measurements, with indentation hardness (HIT) being the most commonly used parameter. However, the definition of indentation hardness [34] is the maximum force divided by the projected area, which is not the case for definition of traditional Vickers hardness. ISO 14577-1 Annex F [34] includes the correlation of HIT to Vickers hardness by converting the projected area to the surface area of contact. The correlation between the two is formulated as $H V=0.0945 \times$ HIT based on the constant ratio of projected area to surface area and unit conversion to $\mathrm{kg} / \mathrm{mm}^{2}$. It is noted that the values calculated in this manner should not be used as a substitute for Vickers hardness.

Another approach is to use Martens hardness (HM), which by definition is the same as traditional Vickers hardness. These two options are compared in Fig. 14 for the measurements of Ref. [23], although not presented there in this form. For comparability, Martens hardness is also converted to kilogrammes per millimetre squared. The ferritic weld metals (WM) have good correlation with Martens hardness and Vickers hardness below $250 \mathrm{HV}$ within the $\pm 5 \%$ limits. At higher values, Martens hardness values are lower than Vickers hardness, indicating that significant in-plane elastic recovery took place after the test force was removed, thus reducing the optically measured diagonals. Indentation hardness (HIT) shows higher deviation at low Vickers hardness values. The values are consistently higher than Vickers hardness, following approximately the $+5 \%$ line above $200 \mathrm{HV}$. Due to the good agreement of Martens hardness below $250 \mathrm{HV}$, it is used for the ferritic samples in the current study.

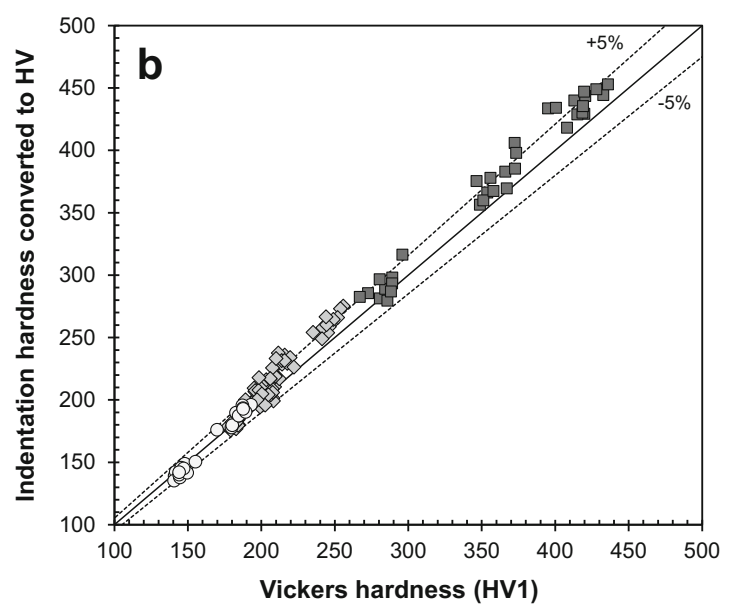

from MPa to $\mathrm{kg} / \mathrm{mm}^{2}$. The measurements are from Ref. [23], although not presented there in this form 


\section{Appendix 2: Grain size contour and hardness values}

This appendix provides an alternative representation of the grain size contour presented in Fig. 12. In order to reveal the microstructure under each indentation, the hardness indentations have been moved below each indentation in Fig. 15. The measured hardness values are presented in Table 4.
Fig. 15 The hardness value for each indentation overlaid on mean grain size contour for the heterogeneous weld metal area A2. Hardness values are shown below each indentation, indicated by the arrows on the left side, to reveal the grain size under the indentations. The grain size colour contour ranges from 99 to $1 \%$ probability level grain size



$50 \mu \mathrm{m}$

Table 4 Martens hardness $(H M)$ values [MPa] for the indentations presented in Figs. 12 and 15

\begin{tabular}{|c|c|c|c|c|c|c|c|c|c|c|c|c|c|}
\hline & & \multicolumn{12}{|c|}{ Indentation number } \\
\hline & & 1 & 2 & 3 & 4 & 5 & 6 & 7 & 8 & 9 & 10 & 11 & 12 \\
\hline \multirow[t]{8}{*}{ Indentation row } & 8 & 2615 & 2587 & 2548 & 2585 & 2515 & 2549 & 2464 & 2557 & 2629 & 2593 & 2283 & 2485 \\
\hline & 7 & 2605 & 2726 & 2609 & 2437 & 2396 & 2068 & 2356 & 2678 & 2320 & 2514 & 2445 & 2530 \\
\hline & 6 & 2657 & 2701 & 2295 & 2559 & 2737 & 2192 & 2592 & 2522 & 2751 & 2332 & 2549 & 2312 \\
\hline & 5 & 2564 & 2405 & 2526 & 2484 & 2239 & 2691 & 2708 & 2488 & 2259 & 2238 & 2259 & 2323 \\
\hline & 4 & 2747 & 2763 & 2554 & 2540 & 2494 & 2432 & 2145 & 2322 & 2411 & 2449 & 2523 & 2113 \\
\hline & 3 & 2641 & 2449 & 2513 & 2309 & 2441 & 2524 & 2170 & 2361 & 2468 & 2256 & 2491 & 2586 \\
\hline & 2 & 2341 & 2743 & 2258 & 2200 & 2720 & 2521 & 2513 & 2292 & 2421 & 2133 & 2360 & 2402 \\
\hline & 1 & 2174 & 2321 & 2200 & 2197 & 2349 & 2143 & 2213 & 2453 & 2596 & 2247 & 2327 & 2396 \\
\hline
\end{tabular}

Indentation $(1,1)$ is located in the lower left corner and indentation $(12,8)$ in the upper right corner of the figures

Open Access This article is distributed under the terms of the Creative Commons Attribution 4.0 International License (http:// creativecommons.org/licenses/by/4.0/), which permits unrestricted use, distribution, and reproduction in any medium, provided you give appropriate credit to the original author(s) and the source, provide a link to the Creative Commons license, and indicate if changes were made.

\section{References}

1. Hall EO (1954) Variation of hardness of metals with grain size. Nature 173:948-9

2. Armstrong RW, Codd I, Douthwaite RM, Petch NJ (1962) The plastic deformation of polycrystalline aggregates. Philos Mag 7:45-58
3. Armstrong RW (1970) The influence of polycrystal grain size on several mechanical properties of materials. Metall Mater Trans 1: 1169-76

4. Tachibana S, Kawachi S, Yamada K, Kunio T (1988) Effect of grain refinement on the endurance limit of plain carbon steels at various strength levels. Nippon Kikai Gakkai Ronbunshu, A Hen/ Transactions Japan Soc Mech Eng Part A 54:1956-61

5. Furukawa M, Horita Z, Nemoto M, Valiev RZ, Langdon TG (1996) Microhardness measurements and the Hall-Petch relationship in an Al-Mg alloy with submicrometer grain size. Acta Mater 44:4619 29. doi:10.1016/1359-6454(96)00105-X

6. Chapetti M, Miyata H, Tagawa T, Miyata T, Fujioka M (2004) Fatigue strength of ultra-fine grained steels. Mater Sci Eng A 381: 331-6. doi:10.1016/j.msea.2004.04.055

7. Hansen N (2004) Hall-Petch relation and boundary strengthening. Scr Mater 51:801-6. doi:10.1016/j.scriptamat.2004.06.002 
8. Hall EO (1951) The deformation and ageing of mild steel: III discussion of results. Proc Phys Soc Sect B 64:747-53

9. Petch NJ (1953) The cleavage strength of polycrystals. J Iron Steel Inst 174:25-8

10. Masumura RA, Hazzledine PM, Pande CS (1998) Yield stress of fine grained materials. Acta Mater 46:4527-34. doi:10.1016/ S1359-6454(98)00150-5

11. Roebuck B (2000) Measurement of grain size and size distribution in engineering materials. Mater Sci Technol 16:1167-74

12. Mingard KP, Roebuck B, Quested P, Bennett EG (2010) Challenges in microstructural metrology for advanced engineered materials. Metrologia 47:S67-82. doi:10.1088/0026-1394/47/2/S08

13. Mingard KP, Roebuck B, Bennett EG, Gee MG, Nordenstrom H, Sweetman G et al (2009) Comparison of EBSD and conventional methods of grain size measurement of hardmetals. Int J Refract Met Hard Mater 27:213-23. doi:10.1016/j.jirmhm.2008.06.009

14. Mingard KP, Day AP, Quested PN (2014) Recent developments in two fundamental aspects of electron backscatter diffraction. IOP Conf Ser Mater Sci Eng 55:012011. doi:10.1088/1757-899X/55/ $1 / 012011$

15. Mingard KP, Quested PN, Peck MS (2012) Determination of grain size by EBSD - Report on a round robin measurement of equiaxed Titanium

16. ISO (2012) ISO 13067 - Microbeam analysis. Electron backscatter diffraction. Measurement of average grain size

17. Kurzydlowski KJ, Bucki JJ (1993) Flow stress dependence on the distribution of grain size in polycrystals. Acta Metall Mater 41:3141-6

18. Weertman JR, Sanders PG, Youngdahl CJ (1997) The strength of nanocrystalline metals with and without flaws. Mater Sci Eng A 234-236:77-82

19. Morita T, Mitra R, Weertman JR (2004) Micromechanics model concerning yield behavior of nanocrystalline materials. Mater Trans 45:502-8. doi:10.2320/matertrans.45.502

20. Berbenni S, Favier V, Berveiller M (2007) Micro-macro modelling of the effects of the grain size distribution on the plastic flow stress of heterogeneous materials. Comput Mater Sci 39:96-105. doi:10. 1016/j.commatsci.2006.02.019

21. Raeisinia B, Sinclair CW, Poole WJ, Tomé CN (2008) On the impact of grain size distribution on the plastic behaviour of polycrystalline metals. Model Simul Mater Sci Eng 16:025001. doi:10. 1088/0965-0393/16/2/025001

22. Ramtani S, Bui HQ, Dirras G (2009) A revisited generalized selfconsistent polycrystal model following an incremental small strain formulation and including grain-size distribution effect. Int J Eng Sci 47:537-53. doi:10.1016/j.ijengsci.2008.09.005

23. Lehto P, Remes H, Saukkonen T, Hänninen H, Romanoff J (2014) Influence of grain size distribution on the Hall-Petch relationship of welded structural steel. Mater Sci Eng A 592:28-39. doi:10.1016/j. msea.2013.10.094

24. Gundersen HJG, Jensen EB (1983) Particle sizes and their distributions estimated from line- and point-sampled intercepts. Including graphical unfolding. J Microsc 131:291-310

25. Gundersen HJG, Jensen EB (1985) Stereological estimation of the volume-weighted mean volume of arbitrary particles observed on random sections. J Microsc 138:127-42

26. ASTM E1382 - 97 (2004) Standard test methods for determining average grain size using semiautomatic and automatic image analysis. ASTM International, West Conshohocken. doi:10.1520/ E1382-97R04

27. Takeuchi S (2001) The mechanism of the inverse Hall-Petch relation of nanocrystals. Scr Mater 44:1483-7. doi:10.1016/S13596462(01)00713-8

28. Fan G, Choo H, Liaw P, Lavernia E (2005) A model for the inverse Hall-Petch relation of nanocrystalline materials. Mater Sci Eng A 409:243-8. doi:10.1016/j.msea.2005.06.073
29. Underwood EE (1970) Quantitative stereology. Addison-Wesley Publishing Co., Reading

30. ASTM E1245 - 03 (2003) Standard practice for determining the inclusion or second-phase constituent content of metals by automatic image analysis. ASTM International, West Conshohocken. doi: 10.1520/E1245-03

31. Lehto P (2015) Aalto University wiki - grain size measurement using Matlab. https://wiki.aalto.fi/display/GSMUM

32. (1991) Guide to the light microscope examination of ferritic steel weld metals, Doc. IIW IX-1533-88. Weld World 29:160-76

33. ASTM E $562-02$ (2002) Standard test method for determining volume fraction by systematic manual point count. ASTM International, West Conshohocken. doi:10.1520/E0562-11

34. ISO 14577-1 (2002) Metallic materials. Instrumented indentation test for hardness and materials parameters. Part 1: Test method. International Organization for Standardization, Geneva

35. Gee M, Mingard K, Roebuck B (2009) Application of EBSD to the evaluation of plastic deformation in the mechanical testing of WC/ Co hardmetal. Int J Refract Met Hard Mater 27:300-12. doi:10. 1016/j.jirmhm.2008.09.003

36. Mingard KP, Roebuck B, Bennett EG, Thomas M, Wynne BP, Palmiere EJ (2007) Grain size measurement by EBSD in complex hot deformed metal alloy microstructures. J Microsc 227:298-308. doi:10.1111/j.1365-2818.2007.01814.x

37. Saukkonen T, Aalto M, Virkkunen I, Ehrnstén U, Hänninen H (2011) Plastic strain and residual stress distributions in an AISI 304 stainless steel BWR pipe weld. 15th Int. Conf. Environ. Degrad, p. 2351-67

38. Radwański K, Wrożyna A, Kuziak R (2015) Role of the advanced microstructures characterization in modeling of mechanical properties of AHSS steels. Mater Sci Eng A 639:567-74. doi:10.1016/j. msea.2015.05.071

39. Nie W, Shang C, You Y, Zhang X, Subramanian S (2013) Microstructure and toughness of the simulated welding heat affected zone in X100 pipeline steel with high deformation resistance. Acta Metall Sin 48:797-806. doi:10.3724/SP.J.1037.2012.00215

40. Sabooni S, Karimzadeh F, Enayati MH, Ngan a HW (2015) Friction-stir welding of ultrafine grained austenitic 304L stainless steel produced by martensitic thermomechanical processing. Mater Des 76:130-40. doi:10.1016/j.matdes.2015.03.052

41. Gazder A, Cao W, Davies CHJ, Pereloma EV (2008) An EBSD investigation of interstitial-free steel subjected to equal channel angular extrusion. Mater Sci Eng A 497:341-52. doi:10.1016/j.msea. 2008.07.030

42. Haušild P, Materna A, Nohava J (2014) Characterization of anisotropy in hardness and indentation modulus by nanoindentation. Metallogr Microstruct Anal 3:5-10. doi:10.1007/s13632-0130110-8

43. Stinville JC, Tromas C, Villechaise P, Templier C (2011) Anisotropy changes in hardness and indentation modulus induced by plasma nitriding of $316 \mathrm{~L}$ polycrystalline stainless steel. Scr Mater 64:37-40. doi:10.1016/j.scriptamat.2010.08.058

44. Patriarca L, Abuzaid W, Sehitoglu H, Maier HJ (2013) Slip transmission in bec FeCr polycrystal. Mater Sci Eng A 588:308-17. doi: 10.1016/j.msea.2013.08.050

45. Soer W, De Hosson JTM (2005) Detection of grain-boundary resistance to slip transfer using nanoindentation. Mater Lett 59:3192-5. doi:10.1016/j.matlet.2005.03.075

46. Durst K, Backes B, Göken M (2005) Indentation size effect in metallic materials: correcting for the size of the plastic zone. Scr Mater 52:1093-7. doi:10.1016/j.scriptamat.2005. 02.009

47. Lilleodden E, Nix W (2006) Microstructural length-scale effects in the nanoindentation behavior of thin gold films. Acta Mater 54: 1583-93. doi:10.1016/j.actamat.2005.11.025 
48. Zhao MC, Yang K, Shan YY (2003) Comparison on strength and toughness behaviors of microalloyed pipeline steels with acicular ferrite and ultrafine ferrite. Mater Lett 57:1496-500. doi:10.1016/ S0167-577X(02)01013-3

49. Fattahi M, Nabhani N, Hosseini M, Arabian N, Rahimi E (2013) Effect of Ti-containing inclusions on the nucleation of acicular ferrite and mechanical properties of multipass weld metals. Micron 45: 107-14. doi:10.1016/j.micron.2012.11.004

50. Seo JS, Lee C, Kim HJ (2013) Influence of oxygen content on microstructure and inclusion characteristics of bainitic weld metals. ISIJ Int 53:279-85

51. Seo JS, Kim HJ, Lee C (2013) Effect of Ti addition on weld microstructure and inclusion characteristics of bainitic GMA welds. ISIJ Int 53:880-6. doi:10.2355/isijinternational.53.880

52. Han R, Lu S, Dong W, Li D, Li Y (2015) The morphological evolution of the axial structure and the curved columnar grain in the weld. J Cryst Growth 431:49-59. doi:10.1016/j.jcrysgro.2015. 09.001

53. Han R, Dong W, Lu S, Li D, Li Y (2014) Modeling of morphological evolution of columnar dendritic grains in the molten pool of gas tungsten arc welding. Comput Mater Sci 95:351-61. doi:10.1016/j. commatsci.2014.07.052

54. Kidess A, Tong M, Duggan G, Browne DJ, Kenjeres S, Richardson I et al (2015) An integrated model for the post-solidification shape and grain morphology of fusion welds. Int J Heat Mass Transf 85: 667-78. doi:10.1016/j.ijheatmasstransfer.2015.01.144

55. Kou S, Le Y (1986) Nucleation mechanism and grain refining of weld metal. Weld J 65:305-13

56. Tan W, Shin YC (2015) Multi-scale modeling of solidification and microstructure development in laser keyhole welding process for austenitic stainless steel. Comput Mater Sci 98:446-58. doi:10. 1016/j.commatsci.2014.10.063 